\title{
Simultaneous Synthesis of Flexible Heat-Exchange Networks with Uncertain Source-Stream Temperatures and Flow Rates
}

\author{
Cheng-Liang Chen* and Ping-Sung Hung \\ Department of Chemical Engineering, National Taiwan University, Taipei 10617, Taiwan, ROC
}

\begin{abstract}
In this paper, a novel strategy for the synthesis of cost-effective flexi ble heat-exchange networks (HENs) that involves specified uncertainties in the source-stream temperatures and flow rates is presented. The problem is decomposed into three main iterative steps: (1) simultaneous HEN synthesis to attain a network configuration with a minimum total annual cost (TAC); (2) flexibility analysis to test whether the network obtained from the synthesis step is feasible in the full disturbance range; and (3) integer cuts to exclude disqualified network configurations, i.e., for those networks not passing the examination of the flexibility analysis, the integer cuts and/or some parameter points will be appended to narrow the search space used for further HEN synthesis. A few iterations of these three steps are required to secure the desirable results. In addition to the theoretical derivation, two examples are included to demonstrate the efficiency of the proposed strategy.
\end{abstract}

\section{Introduction}

As complicated as it is, a standard heat-exchange network (HEN) synthesis problem can be stated as follows: Given hot/cold process streams to be cooled/ heated from nominal supply temperatures to specified target temperatures and heating/cooling utilities, synthesize an HEN configuration to reach some assigned objective(s) such as the minimum utility consumption, the minimum total number of heat-exchange units, the minimum total exchanger area, the minimum total annual cost (TAC), etc. HEN synthesis is by far one of the most developed fields for which many techniques, such as evolutionary design methods (e.g., pinch design method $^{1}$ ) or mathematical programming approaches (e.g., sequential ${ }^{2}$ or simultaneous optimization ${ }^{3,4}$ ), have been proposed. ${ }^{5} \mathrm{~A}$ review with an annotated bibliography on HEN synthesis methods proposed in the 20th century can be found in the recent literature; ${ }^{6}$ therein, a timeline of innovation and major discoveries in HEN synthesis are also addressed.

Such issues as utility consumption, matching numbers, and total area for HEN synthesis and the capability of HENs for feasible operation under possible variations of source-stream temperatures and flow rates-the typical design objectives-have also been emphasized in some articles. ${ }^{7-12} \mathrm{~F}$ or example, Floudas and Grossmann ${ }^{11}$ proposed a novel sequential synthesis method that combines the multiperiod mixed-integer linear programming (M-MILP) transshipment model, used for generating the set of stream matches; the nonlinear programming (NLP) formulation, used for synthesizing the multiperiod networks; and the active set strategy, 10 used for performing the flexibility analysis over the full disturbance range at the levels of matches and structures. Illustrations show that a few iterations are usually required in the synthesis and flexibility analysis stages. However, the formulation and the synthesis procedure are somewhat tedious in treating the partitioning of temperature intervals under

* To whom correspondence should be addressed. Tel.: 8862-23636194. Fax: 886-2-23623040. E-mail: CCL @ntu.edu.tw uncertain inlet temperatures. Aaltol $a^{12}$ proposed using a multiperiod simultaneous mixed-integer nonlinear programming (MINLP) model for minimizing the total annual cost (TAC) and generating a flexible heatexchange network directly. Not relying on a sequential decomposition, this method seems simple and straightforward. However, the operational feasibility of the resulting network is not guaranteed because only a finite number of operating conditions are considered during the design.

In this paper, the authors try to take advantage of both approaches ${ }^{11,12}$ for the synthesis of a flexible heatexchange network. In this novel approach, the flexible HEN synthesis problem is decomposed into three main iterative steps: simultaneous HEN synthesis for considering a finite number of operating conditions, flexibility analysis for testing the feasibility of the network over the full disturbance ranges, and integer cuts for excluding the disqualified networks. In the simultaneous synthesis step, the problem is formulated as a multiperiod mixed-integer nonlinear programming (MMMINLP) for minimizing the TAC of the network based on the stagewise superstructure proposed by $Y e e$ and Grossmann. 3,4 In the flexibility analysis step, we solve the flexibility index evaluation problem for the network structure obtained from the synthesis step by directly applying the active set strategy. ${ }^{10,11}$ Should the resulting network(s) not pass the flexibility test, the associated integer cuts would be appended to the search space to exclude the same network(s) from consideration. In addition, a set of additional extreme parameter points can also be included to reduce the feasible space and to accelerate the design process. To obtain the final qualified network configuration, several iterations of such network synthesis and flexibility analysis steps might be required. According to the results of simulations with examples modified from those of Floudas and Grossmann, ${ }^{11}$ the efficiency of the proposed flexible HEN synthesis method is quite satisfactory. 


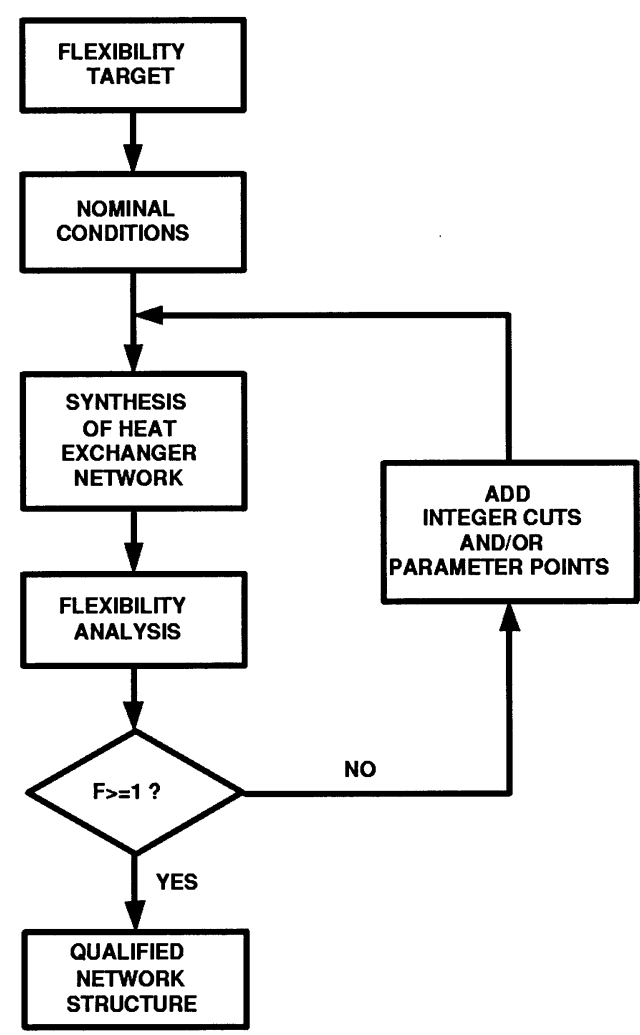

Figure 1. Proposed strategy for flexible HEN synthesis.

\section{Problem Definition and Outline of the Proposed F lexible HEN Synthesis Strategy}

An HEN synthesis problem with $\mathrm{N}_{\mathrm{H}}$ hot streams and $\mathrm{N}_{c}$ cold streams al ong with possible variations in input temperatures and heat capacity flow rates is considered here. Let $\theta$ denote the vector of uncertain parameters with the nominal value $\theta^{\mathbf{0}}$. Suppose $\Delta \theta^{-}$and $\Delta \theta^{+}$are the maximum expected deviations of these uncertain parameters in the negative and positive directions. The flexible HEN synthesis problem can then be defined as synthesizing a cost-effective heat-exchange network that is feasible for all possible operating points contained in $\mathrm{P}(\delta=1)$, ${ }^{11}$ where

$$
\mathrm{P}(\delta)=\left\{\theta \mid \theta^{\mathbf{0}}-\delta \Delta \theta^{-} \leq \theta \leq \theta^{\mathbf{0}}+\delta \Delta \theta^{+}\right\}
$$

As is pointed out in the literature, $7,10,13$ this problem is difficult to solve directly because it involves a maxmin-max constraint. In other words, the feasible region defined by the inequality energy balance constraints is nonconvex, ${ }^{14}$ so the critical point that confines the solution might not rest on the vertexes of the polyhedral region of uncertainty. It is this difficulty that motivates us to separate the flexible HEN design into iterative steps, as depicted in Figure 1. Except for the finite extreme operating conditions considered in the synthe sis to narrow the search space, the desired ranges of operating flexibility, that is, the feasible ranges for uncertain source-stream temperatures and/or flow rates, should be assigned at first. I nstead of directly including this flexibility target in the HEN synthesis, the allowable operational range is evaluated and qualified for a candidate network structure. Those disqualified networks are excluded by appending the integer cuts in the search space for subsequent network synthesis. The proposed strategy for the flexible HEN synthesis involves the following three main iterative steps:
1. Synthesis of a Multiperiod Network via Simultaneous Optimization. According to the superstructure-based multiperiod MINLP formulation for HEN synthesis discussed in section 3, a heat-exchange network can be synthesized by means of any existing mixed-integer nonlinear optimization algorithm. Several extreme operating periods can be considered simultaneously to reduce the search space, al though the number of continuous variables is increased dramatically. The flexibility requirement is not directly taken into account in this synthesis step to simplify the calculation.

2. Evaluation of the Flexibility Index. In this stage, the flexibility index of the network resulting from the previous synthesis step is evaluated to determine whether the current network satisfies the previously assigned flexibility target, that is, whether the network can be operated over the full range of possible input stream temperatures and flow rates. Here, the flexibility index is determined by using the active set strategy proposed by Grossmann and Floudas ${ }^{10}$ and reviewed in section 4 to take into account the possibility of nonextreme critical points. If the current HEN structure meets the requirement of the flexibility target, it can be directly accepted as a qualified network to terminate the search. On the other hand, if the resulting flexibility index does not satisfy the target, then a new network structure with improved operational flexibility must be found by using the procedure listed in the following step.

3. Integer Cuts To Exclude the Disqualified Networks. For disqualified network structures, the integer cuts expressed in eq 15 and/or some additional extreme points can be appended to the original structure to reduce the search space and then go back to the synthesis step for iteration to find a new candidate network.

Several iterations of these three steps are sometimes required to attain a qualified configuration. Nevertheless, the proposed strategy is attractive enough because it prevents the necessity to include a large number of constraints and operating points directly in the formulation. To illustrate how to carry out the whole synthesis procedure, the authors present two examples in section 6. Through the numerical simulations, it can be verified that the proposed strategy is easy to implement and can provide a feasible and balanced solution for the heatexchange network synthesis problem.

\section{Synthesis of Multiperiod Heat-Exchange Networks}

The stagewise superstructure proposed by Yee and Grossmann ${ }^{3,4}$ is applied to construct the configuration of a heat-exchange network, as it is suitable for formulating a simultaneous solution that involves the consideration of total utility consumption, the total number of matches, and the total area of heat-exchange units. A two-stage superstructure with two hot and two cold streams is shown in Figure 2 for reference; the meanings of relevant notations in the structure can be found in either Yee and Grossmann ${ }^{3,4}$ or the Nomenclature section.

Instead of directly considering all possible combinations of uncertain input temperatures and heat capacity flow rates for the flexible network synthesis, only a finite number of extreme operating conditions are taken into account for network design to reduce the search space. The mathematical programming formulation for minimizing the total annual cost, TAC, which includes the 
average costs of hot and cold utility consumption over a finite number of operating points and the annual costs of installation and material of the heat-exchange units, can be summarized as follows $3,4,15$

$$
\begin{aligned}
& \min _{\mathbf{x} \in \Omega} T A C=\frac{1}{N_{V}+1}\left(\sum_{\forall n \in V T \forall i \in H P} \sum_{c u} C_{c c u}^{(n)}+\right. \\
& \left.\sum_{\forall n \in V T \forall j \in C P} \sum_{h u} q h u_{j}^{(n)}\right) \\
& +\sum_{\forall i \in H P \forall \forall \in C P \forall \forall \in S T} \sum_{i j}\left[\max _{\forall n \in V T}\left(\frac{q_{i j k}^{(n)}}{U_{i j} L_{M T D}^{(n)}}\right)\right] \\
& +\sum_{\forall j \in \mathrm{CP}} C_{h u, j}\left[\max _{\forall n \in V T}\left(\frac{q u_{j}^{(n)}}{U_{h u, j} L_{M T D_{h u, j}^{(n)}}^{(n)}}\right)\right] \\
& +\sum_{\forall i \in H P} C_{i, c u}\left[\max _{\forall n \in V T}\left(\frac{q u_{i}^{(n)}}{U_{i, c u} L M T D_{i, c u}^{(n)}}\right)\right]
\end{aligned}
$$

where $\mathbf{x}$ and $\Omega$ denote the design variables and the feasible search space comprising all material/energy balance constraints and relevant logical constraints, respectively. $\mathrm{VT}=\left\{0,1, \ldots, \mathrm{N}_{\mathrm{V}}\right\}$ is the index set, in which zero denotes the nominal conditions (or the base case), for numbering a limited number of extreme operating conditions used for finding the optimal final structure. These possi ble operating vertexes are applied here to hel $p$ reduce the search space in the design stage.

$$
\mathbf{x} \equiv\left\{\begin{array}{l}
z_{i j k}, z \mathrm{zu}_{i}, z h u_{j} ; \\
t_{i k}^{(n)}, t_{j k}^{(n)}, t_{i, N_{T}+1}^{(n)}, t_{j, N_{T}+1}^{(n)} ; \\
d t_{i j k}^{(n)}, d t_{i j, N_{T}+1}^{(n)}, d t c u_{i}^{(n)}, d t h u_{j}^{(n)} ; \\
q_{i j k}^{(n)}, q c u_{i}^{(n)}, q h u_{j}^{(n)} ; \\
\forall i \in H P, j \in C P, k \in S T, n \in V T
\end{array}\right\}
$$

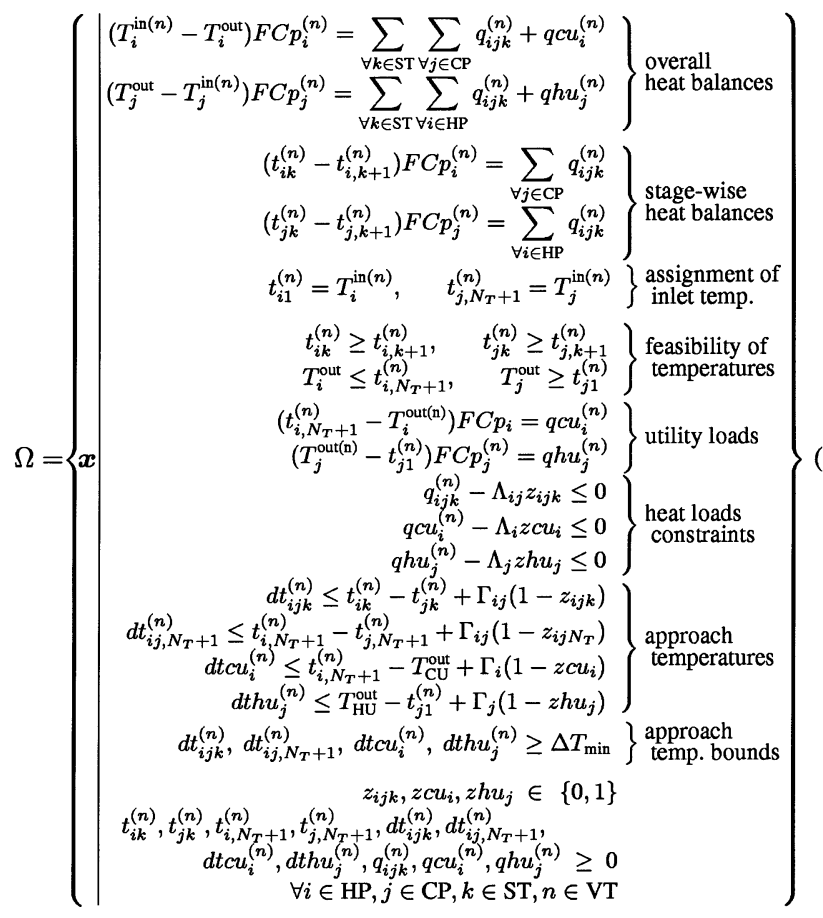

Here, LMTD $_{i j k}$ is the log-mean approaching temperature for the matching of hot stream $i$ and cold stream $j$ at the kth stage. Chen's approximation is used for LMT$D_{i j k .}{ }^{16}{ }^{2} M T D_{i, c u}$ and $L M T D_{h u, j}$ are defined and approximated similarly.

$$
\begin{aligned}
& \operatorname{LMTD}_{i j k}=\frac{\left(t_{i k}-t_{j k}\right)-\left(t_{i, k+1}-t_{j, k+1}\right)}{n_{\frac{t_{i, k+1}}{t_{i k}-t_{j k}}}} \\
& \approx\left[\left(t_{i k}-t_{j k}\right)\left(t_{i, k+1}-t_{j, k+1}\right) \times\right. \\
& \left.\left(\frac{t_{i k}+t_{i, k+1}}{2}-\frac{t_{j k}+t_{j, k+1}}{2}\right)\right]^{1 / 3}
\end{aligned}
$$

Note that the inclusion of each of the extreme periods increases the total number of continuous variables; therefore, the designer should make a tradeoff between the number of variables and the search space. There are a total of $4 \mathrm{~N}_{\mathrm{H}}+\mathrm{N}_{\mathrm{C}}$ vertexes for an HEN synthesis problem with $\mathrm{N}_{\mathrm{H}}$ hot and $\mathrm{N}_{\mathrm{C}}$ cold streams that can vary in temperatures and flow rates. It is impractical to include simultaneously all of those operating extremes for resilient network design because of the dramatic increase of the number of continuous variables for each of these extreme situations. Marselle et al. ${ }^{7}$ suggested considering the states that tend to maximize the need for exchangers, coolers, and heaters, which are determined as follows. The case of all streams with the maximum heat capacity flow rates and with the maximum (minimum) supply temperatures for all hot (cold) streams tends to result in a network configuration with the maximum heat-exchange area. The instance of the highest cooling requirement (i.e., all hot streams have the upper-bound temperatures and heat capacity flow rates) and the lowest cooling capability (all cold streams have the upper-bound temperatures and the lowerbound heat capacity flow rates) tends to be a network consuming the maximum cooling utility. A network in which the highest heating requirement for the cold streams (minimum temperatures and maximum flow rates) is paired with the lowest heating capability for hot streams (minimum temperatures and flow rates) needs the maximum heating utility. As pointed out by Marselle et al., 7 a network that can handle these three extreme periods does not necessarily imply that all states within the disturbance range can be operated adequately. Although a quantitative flexibility analysis is still rel evant to clarify the feasible operating range of the network, the network combining these three extreme periods represents a highly resilient network candidate. Other vertexes are sel dom applied for design in the literature except for problems considering uncertain supply temperatures only. ${ }^{17}$

\section{Flexibility Analysis}

The solution of eq 2 is a heat-exchange network with a minimum TAC under a specific configuration that satisfies multiple extreme operating conditions. When the resulting network is applied to a process with the consideration that the source-stream temperatures and heat capacity flow rates can vary in the full range of uncertainty, its flexibility can be measured by the flexibility index proposed by Swaney and Grossmann. ${ }^{9}$ To carry out the flexibility analysis, all rel evant equality 


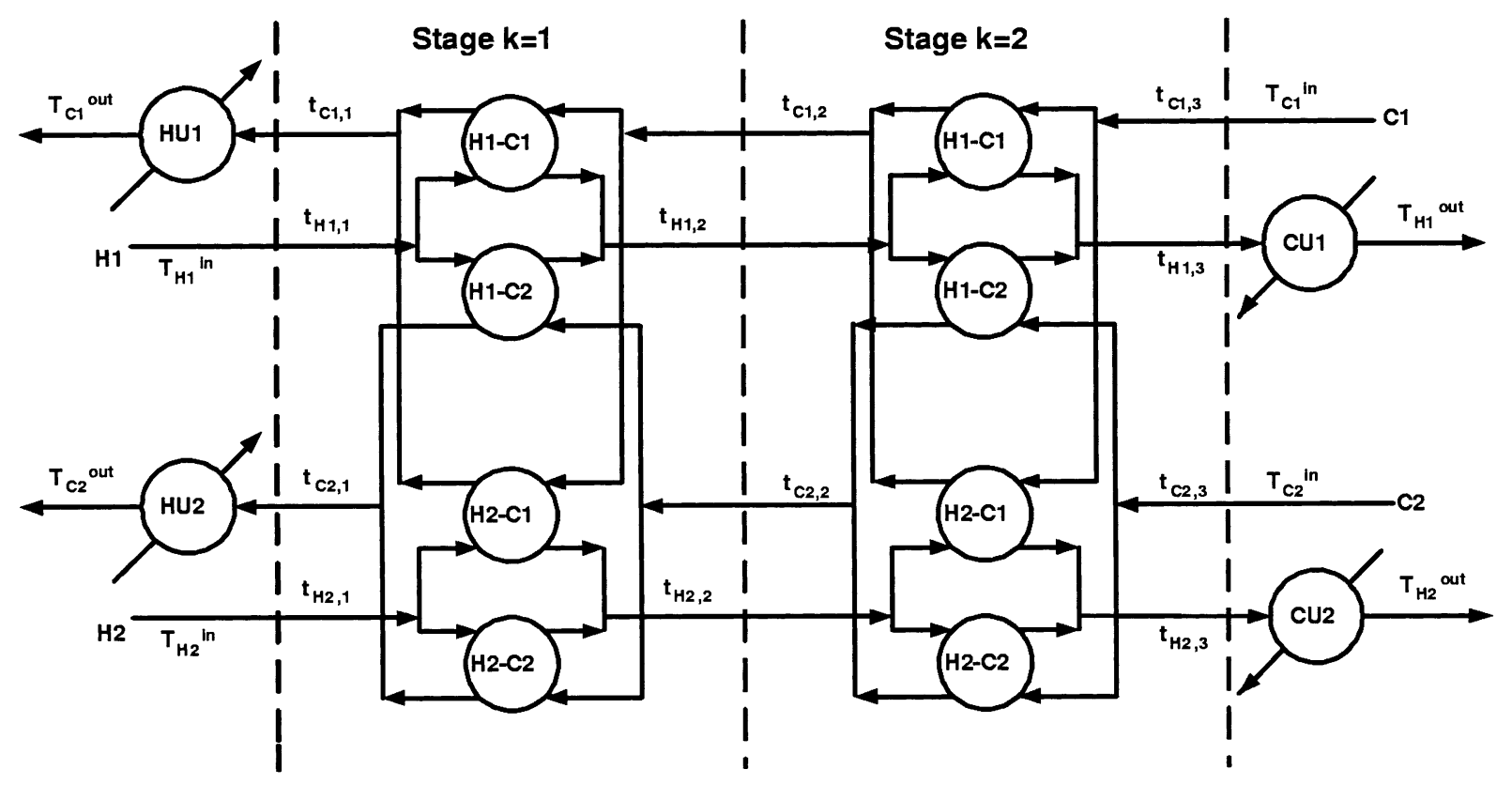

Figure 2. Two-stage superstructure.

and inequality constraints for the heat-exchange network model can be reorganized as described in eqs 6 and 7. It should be noted that the overall heat balances are not included because they can be obtained by combining other independent equalities.

$$
\begin{aligned}
& \mathbf{h}(\mathbf{d}, \mathbf{u}, \mathbf{w}, \theta)=\left(\begin{array}{l}
\sum_{\forall j \in C P} q_{i j k}-\left(t_{i k}-t_{i, k+1}\right) F C p_{i} \\
\sum_{\forall i \in H P} q_{i j k}-\left(t_{j k}-t_{j, k+1}\right) F C p_{j} \\
q C u_{i}-\left(t_{i, N_{T}+1}-T_{i}^{\text {out }}\right) F C p_{i} \\
q h u_{j}-\left(T_{j}^{\text {out }}-t_{j 1}\right) F C p_{j} \\
T_{i}^{i n}-t_{i 1} \\
T_{j}^{i n}-t_{j, N_{T}+1}
\end{array}\right)=0 \\
& \mathbf{g}(\mathbf{d}, \mathbf{u}, \mathbf{w}, \theta)=\left(\begin{array}{l}
t_{i, k+1}-t_{i k} \\
t_{j, k+1}-t_{j k} \\
T_{i}^{\text {out }}-t_{i, N_{T}+1} \\
t_{j 1}-T_{j}^{\text {out }} \\
\Delta T_{\min }+t_{j k}-t_{i k} \\
\Delta T_{\min }+t_{j, N_{T}+1}-t_{i, N_{T}+1} \\
\Delta T_{\text {min }}+T_{C U}^{\text {out }}-t_{i, N_{T}+1} \\
\Delta T_{\min }+t_{j, 1}-T_{H U}^{\text {out }}
\end{array}\right) \leq 0
\end{aligned}
$$

The variables in these equations are classified into four categories. $\theta$ is the vector of uncertain parameters (i.e., temperatures and flow rates defined in eq 1). The design variables d, obtained from the synthesis step, define the network structure and the sizes of the heat-exchange units. The control variables $\mathbf{u}$ represent the degrees of freedom in the operation of the network. w, the state variables, can be expressed as implicit functions of control variables $\mathbf{u}$ and uncertain parameters $\theta$ by solving the independent equality constraints.

$$
\mathbf{h}(\mathbf{d}, \mathbf{u}, \mathbf{w}, \theta)=0 \rightarrow \mathbf{w}=\mathbf{w}(\mathbf{d}, \mathbf{u}, \theta)
$$

Thus, the inequalities of the network can be represented by the following equation, where $\mathrm{Cl}$ is the index set of condensed inequalities

$$
\mathrm{g}_{\mathrm{m}}[\mathbf{d}, \mathbf{u}, \mathbf{w}(\mathbf{d}, \mathbf{u}, \theta), \theta]=\mathrm{f}_{\mathrm{m}}(\mathbf{d}, \mathbf{u}, \theta) \leq 0 \quad \forall \mathrm{m} \in \mathrm{Cl}
$$

By rearranging the related equations, the flexibility index problem of a network can be formulated as the following mixed-integer nonlinear programming problem $^{10,11,15}$

$$
\begin{aligned}
& \mathscr{F}=\min _{\theta, \mathbf{u}, \mathrm{s}_{m}, \lambda_{m}, y_{m}, \delta} \delta \\
& \text { s.t. } \mathrm{s}_{\mathrm{m}}+\mathrm{f}_{\mathrm{m}}(\mathbf{d}, \mathbf{u}, \theta)=0
\end{aligned}
$$

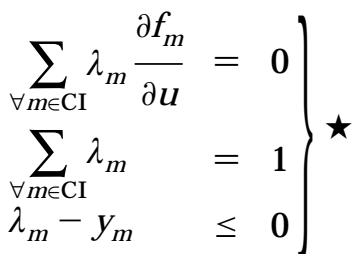

$$
\begin{aligned}
& \mathrm{s}_{\mathrm{m}}-\mathrm{V}\left(1-\mathrm{y}_{\mathrm{m}}\right) \leq 0 \\
& \sum_{\forall \mathrm{m} \in \mathrm{Cl}} \mathrm{y}_{\mathrm{m}}=\mathrm{n}_{\mathrm{u}}+1 \\
& \theta \in \mathrm{P}(\delta), \quad \mathrm{y}_{\mathrm{m}} \in\{0,1\} \\
& \delta, \lambda_{\mathrm{m}}, \mathrm{s}_{\mathrm{m}} \geq 0, \quad \forall \mathrm{m} \in \mathrm{Cl}
\end{aligned}
$$

In these equations, Frepresents the quality of flexibility level, where an $\mathscr{F}$ with value of less than 1 means that the network is not operable within the full range of definite uncertain parametric bounds; $\mathrm{s}_{\mathrm{m}}$ are slack variables; $\lambda_{\mathrm{m}}$ are Kuhn-Tucker multipliers; $\mathrm{y}_{\mathrm{m}}=1$ indicates active constraints; $V$ is a sufficiently large real number; and $n_{u}$ is the number of control variables $\mathbf{u}$. Details of the above MINLP formulation can be found in the literature. ${ }^{10,11}$

The active set strategy, illustrated in eq 10 for solving the mixed-integer optimization problem, consists of three basic steps. ${ }^{10,11}$ First, the active candidate sets 
should be identified. Let $\mathrm{N}_{\mathrm{AS}}=\left\{1, \ldots, \mathrm{n}_{\mathrm{AS}}\right\}$ denote the index set of all possible combinations for the active constraints and $\mathrm{AS}(\mathrm{k})$ represent the kth index set of the active constraints. Then, a value of $\delta^{\mathrm{k}}$ for the kth active candidate set can be obtained by solving the following nonlinear programming (NLP) problem ${ }^{11}$

$$
\delta^{\mathrm{k}}=\min _{\theta, \mathbf{u}, \delta} \delta
$$

$$
\begin{array}{cc}
\text { s.t. } & \mathrm{f}_{\mathrm{m}}(\mathbf{d}, \mathbf{u}, \theta)=0 \\
& \theta \in \mathrm{P}(\delta) \\
& \delta \geq 0
\end{array}
$$$$
\forall \mathrm{m} \in \mathrm{AS}(\mathrm{k}) \subseteq \mathrm{Cl}
$$

The solution of the flexibility index problem is given by

$$
\mathscr{F}=\min _{\forall k \in \mathrm{N}_{\mathrm{AS}}} \delta^{k}
$$

Notice that, for problems in which there is no control variable (i.e., $n_{u}=0$ ), the flexibility analysis problems are much simpler. ${ }^{10}$ In such a case, the stationary conditions in eq 10, that is, the three relations marked with a $\star$ and the associated Kuhn-Tucker multipliers $\lambda_{\mathrm{m}}$, can be eliminated. In this condensed formulation, only one constraint is allowed to be active for each active set. Equation 10 can thus be decomposed in terms of each individual constraint, that is, $\mathrm{AS}(\mathrm{k})=\{\mathrm{k}\}, \forall \mathrm{k} \in$ $\mathrm{N}_{\text {As. }}$. The flexibility index problem is therefore simplified significantly.

\section{Integer Cuts for Excluding the Disqualified Networks}

If an HEN resulting from the previous formulation is not qualified in the flexibility test, a different HEN should be proposed as the new candidate. To avoid coming up with a same HEN structure that has been eliminated in the previous $n_{R}$ iterations, one should add some constraints in the $\left(n_{R}+1\right)$ st synthesis formulation. Herein, two kinds of networks are guaranteed to be brand-new: one that has at least one different unit from any earlier eliminated network and one that whose units are only part of those of any earlier eliminated network. These two conditions can be expressed by the following logic constraints for the $\left(n_{R}+1\right)$ st network

Case 1

$$
\begin{aligned}
\sum_{\forall i \in H P \forall j \in C P \forall \forall \in S T} \sum_{i j}\left(1-z_{i j k}\right) z_{i j k}^{n_{R}+1}+ & \sum_{\forall i \in H P}\left(1-z_{i, c u}\right) z_{i, c u}^{n_{R}+1}+ \\
& \sum_{\forall j \in C P}\left(1-z_{h u, j}\right) z_{h u, j}^{n_{R}+1} \geq 1
\end{aligned}
$$

and

$$
\begin{aligned}
\sum_{\forall i \in H P \forall j \in C P \forall \forall \in S T} \sum_{i j k} z_{i j k}^{n_{R}+1}+\sum_{\forall i \in H P} z_{i, c u}^{\prime} z_{i, c u}^{n_{R}+1}+ \\
\sum_{\forall j \in C P} z_{h u, j} z_{h u, j}^{n_{R}+1} \leq n_{S N}^{\prime}
\end{aligned}
$$

Case 2

$$
\begin{aligned}
\sum_{\forall i \in H P \forall j \in C P \forall \forall \in S T} \sum_{j}\left(1-z_{i j k}\right) z_{i j k}^{n_{R}+1}+ & \sum_{\forall i \in H P}\left(1-z_{i, c u}\right) z_{i, c u}^{n_{R}+1}+ \\
& \sum_{\forall j \in C P}\left(1-z_{h u, j}\right) z_{h u, j}^{n_{R}+1} \geq 0
\end{aligned}
$$

Table 1. Cost Data for Example 1

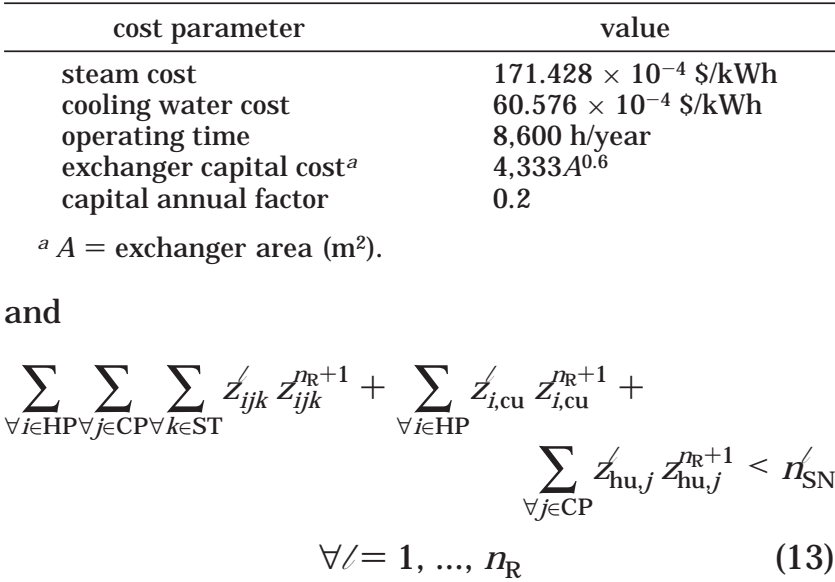

Here, $z_{\text {. }}$ and $\mathrm{n}_{\mathrm{SN}}^{\prime}$ denote the associated integer value and the total number of sel ected units, respectively, of the $/$ th eliminated network, $l=1, \ldots, \mathrm{n}_{\mathrm{R}}$. Let a new binary variable $z_{d}$ denote the toggle switch of these two acceptable conditions, i.e., $z_{d}=1$ for case 1 and $z_{d}=0$ for case 2 . Then, the above logic constraints can be expressed as

$$
\begin{gathered}
\sum_{\forall i \in H P \forall j \in C P \forall \forall \in S T} \sum_{\forall}\left(1-z_{i j k}\right) z_{i j k}^{n_{R}+1}+\sum_{\forall i \in H P}\left(1-z_{i, c u}^{\prime}\right) z_{i, c u}^{n_{R}+1}+ \\
\left.\sum_{\forall i \in H P \forall j \in C P \forall \forall \in S T} \sum_{\forall j \in C P} z_{i j k} z_{i j k}^{n_{R}+1}+\sum_{h u, j}\right) z_{h u, j}^{n_{R}+1} \geq z_{d} \\
\sum_{\forall i \in H P} z_{i, c u}^{\prime} z_{i, c u}^{n_{R}+1}+ \\
z_{h u, j}^{\prime} z_{h u, j}^{n_{R}+1} \leq n_{S N}^{\prime}-1+z_{d} \\
z_{d}^{\prime} \in\{0,1\}, \quad l=1, \ldots, n_{R}
\end{gathered}
$$

These two expressions can be further combined into a single integer cut equation. These integer cuts in the search space can guarantee that a network candidate different from all previously disqualified configurations is attained

$$
\begin{aligned}
& 2\left(\sum_{\forall i \in H P \forall j \in C P \forall \forall \in S T} \sum_{i j k} z_{i j k}^{n_{R}+1}+\sum_{\forall i \in H P} z_{i, c u} z_{i, c u}^{n_{R}+1}+\right. \\
& \left.\sum_{\forall j \in C P} z_{h u, j} z_{h u, j}^{n_{R}+1}\right)-\left(\sum_{\forall i \in H P \forall j \in C P \forall \forall \in S T} \sum_{i j k} z_{i j}^{n_{R}+1}+\sum_{\forall i \in H P} z_{i, c u}^{n_{R}+1}+\right. \\
& \left.\sum_{\forall j \in C P} z_{h u, j}^{n_{R}+1}\right) \leq n_{S N}^{\prime}-1 \\
& l=1, \ldots, \mathrm{n}_{\mathrm{R}}
\end{aligned}
$$

\section{Numerical Examples}

Examples adapted from Floudas and Grossmann ${ }^{11}$ are used here to demonstrate the efficiency of the proposed strategy. To solved the MINLP for HEN models, the General Algebraic Modeling System (GAMS) ${ }^{18}$ is used as the main solution tool. The MINLP and NLP solvers are SBB and CONOPT3 for both examples.

Example 1. A Two-Hot/Two-Cold Streams Problem. The first example involves two hot and two cold streams $\left(\mathrm{N}_{\mathrm{H}}=2, \mathrm{~N}_{\mathrm{C}}=2\right)$ al ong with steam and cooling water, respectively, as the heating and cool ing utilities. The data for the problem, including the nominal operating conditions as well as three periods of extreme operating conditions, are listed in Tables 1 and 2 . Under 
Table 2. Nominal and Multiperiod Operating Conditions for Example 1a

\begin{tabular}{|c|c|c|c|}
\hline process streams & $\begin{array}{c}\text { heat-capacity } \\
\text { flow rate FCp } \\
(\mathrm{kW} / \mathrm{K})\end{array}$ & $\begin{array}{c}\text { input } \\
\text { temperature } \\
T \text { in }(K)\end{array}$ & $\begin{array}{c}\text { output } \\
\text { temperature } \\
T \text { out }(K)\end{array}$ \\
\hline \multicolumn{4}{|c|}{ nominal conditions (base case) } \\
\hline hot stream $1(\mathrm{H} 1)$ & 1.4 & 583 & 323 \\
\hline hot stream 2 (H2) & 2.0 & 723 & 553 \\
\hline cold stream 1 (C1) & 3.0 & 313 & 393 \\
\hline cold stream 2 (C2) & 2.0 & 388 & 553 \\
\hline hot utility (HU) & - & 573 & 573 \\
\hline cold utility (CU) & - & 303 & 323 \\
\hline \multicolumn{4}{|c|}{ period 1 (maximizing exchange area) } \\
\hline hot stream $1(\mathrm{H} 1)$ & 1.8 & 593 & 323 \\
\hline hot stream 2 (H2) & 2.0 & 723 & 553 \\
\hline cold stream 1 (C1) & 3.0 & 313 & 393 \\
\hline cold stream 2 (C2) & 2.4 & 383 & 553 \\
\hline \multicolumn{4}{|c|}{ period 2 (including maximum cooling load) } \\
\hline hot stream $1(\mathrm{H} 1)$ & 1.8 & 593 & 323 \\
\hline hot stream 2 (H2) & 2.0 & 723 & 553 \\
\hline cold stream 1 (C1) & 3.0 & 313 & 393 \\
\hline cold stream 2 (C2) & 1.6 & 393 & 553 \\
\hline \multicolumn{4}{|c|}{ period 3 (including maximum heating load) } \\
\hline hot stream 1 (H1) & 1.0 & 573 & 323 \\
\hline hot stream $2(\mathrm{H} 2)$ & 2.0 & 723 & 553 \\
\hline cold stream 1 (C1) & 3.0 & 313 & 393 \\
\hline cold stream 2 (C2) & 2.4 & 383 & 553 \\
\hline
\end{tabular}

the conditions that the expected maximum operating disturbances are $\pm 10 \mathrm{~K}$ for stream hot- 1 and $\pm 5 \mathrm{~K}$ for stream cold- 2 in temperature and $\pm 0.4 \mathrm{~kW} \mathrm{~K}^{-1}$ for both streams hot- 1 and cold- 2 in heat capacity flow rate, the objective is to derive a heat-exchange network configuration that is feasible for the specified disturbance range and features the minimum TAC. The minimum number of superstructure stages, $\mathrm{N}_{\mathrm{T}}$, is set at 2 because $\max \left\{\mathrm{N}_{\mathrm{H}}, \mathrm{N}_{\mathrm{C}}\right\}=2 .^{3}$ The proposed iterative solution strategy is illustrated in the following discussion. To show the effect of appending the extreme operating periods mentioned in section 3 and the integer cuts on the reduction of the search space, one extreme period and one integer cut per iteration are added to the model until a feasible solution is achieved.

1. Iteration 1. To start, by applying the nominal conditions to eqs $2-4$, a network with a minimum TAC of $\$ 25,958 \$$ year is obtained, and its structure and the data on flow rate and temperature are shown in Figure 3 , where the heat-exchange load for each unit is boxed. Let $\mathrm{SN}^{1}=\left\{\mathrm{z}_{112}^{1}, \mathrm{z}_{211}^{1}, \mathrm{z}_{221}^{1}, \mathrm{zcu}_{1}^{1}\right\}$ denote the set of selected units of the first candidate network. The constraints in eqs 6 and 7 are then utilized to examine this network. Because there are six equations and six unknowns, no variable is left for control (i.e., $n_{u}=0$ ). Solving the nonlinear programming problem, eq 11, for each active set of constraints results in the flexibility index value of $\mathscr{F}=0.1311$ (details of the evaluation can be found in Appendix A). Such a low value of the flexibility index implies that the network structure designed for the base case will be infeasible for some possible input conditions within the disturbance range. Thus, to obtain a better network, an additional parameter point that embraces the maximum total heatexchange load (i.e., $\mathrm{F}_{\mathrm{H} 1}^{\mathrm{U}}, \mathrm{F}_{\mathrm{C} 2}^{\mathrm{U}}, \mathrm{T}_{\mathrm{H} 1}^{\mathrm{U}}, \mathrm{T}_{\mathrm{C} 2}^{\mathrm{L}}$ ) and the integer cut, eq 15 , with $\mathrm{SN}^{1}$ and $\mathrm{n}_{\mathrm{SN}}^{1}=4$ to exclude the current network configuration are appended to the network synthesis problem.

2. Iteration 2. With the integer cut for excluding the current network obtained from iteration 1, eqs 2-4 are solved again by al so considering the conditions of period 1 as well as the nominal operating case. The resulting network, shown in Figure 4, features a TAC of \$35,$219 \$ /$ year, with the set of selected units $\mathrm{SN}^{2}=\left\{\mathrm{z}_{122}^{2}\right.$, $\left.\mathrm{z}_{211}^{2}, \mathrm{z}_{221}^{2}, \mathrm{zcu}_{1}^{2}\right\}$ and $\mathrm{n}_{\mathrm{SN}}^{2}=4$. Equations 6 and 7 are then employed to test the operation feasibility of this network structure under the specified operating range. Here, because the numbers of equations and unknowns are the same (six equations and six unknowns), no additional control variable is left $\left(n_{u}=0\right)$. The solution of the nonlinear programming problem, eq 11 , again shows that $\mathscr{F}=0.1847$ is still less than 1 , and therefore, the network is again unqualified. Appendix $A$ shows the detailed evaluation procedures. Once again, a new parameter point that embraces the maximum cooling load (i.e. $\mathrm{F}_{\mathrm{H} 1}^{\mathrm{U}}, \mathrm{F}_{\mathrm{C} 2}^{\mathrm{L}}, \mathrm{T}_{\mathrm{H} 1}^{\mathrm{U}}, \mathrm{T}_{\mathrm{C} 2}^{\mathrm{U}}$ ) and the integer cuts to rule out the same networks obtained from the first and the second iterations are introduced into the search space. Next comes the third iteration.

3. Iteration 3. From the same eqs 2-4 with the application of the nominal operating conditions and

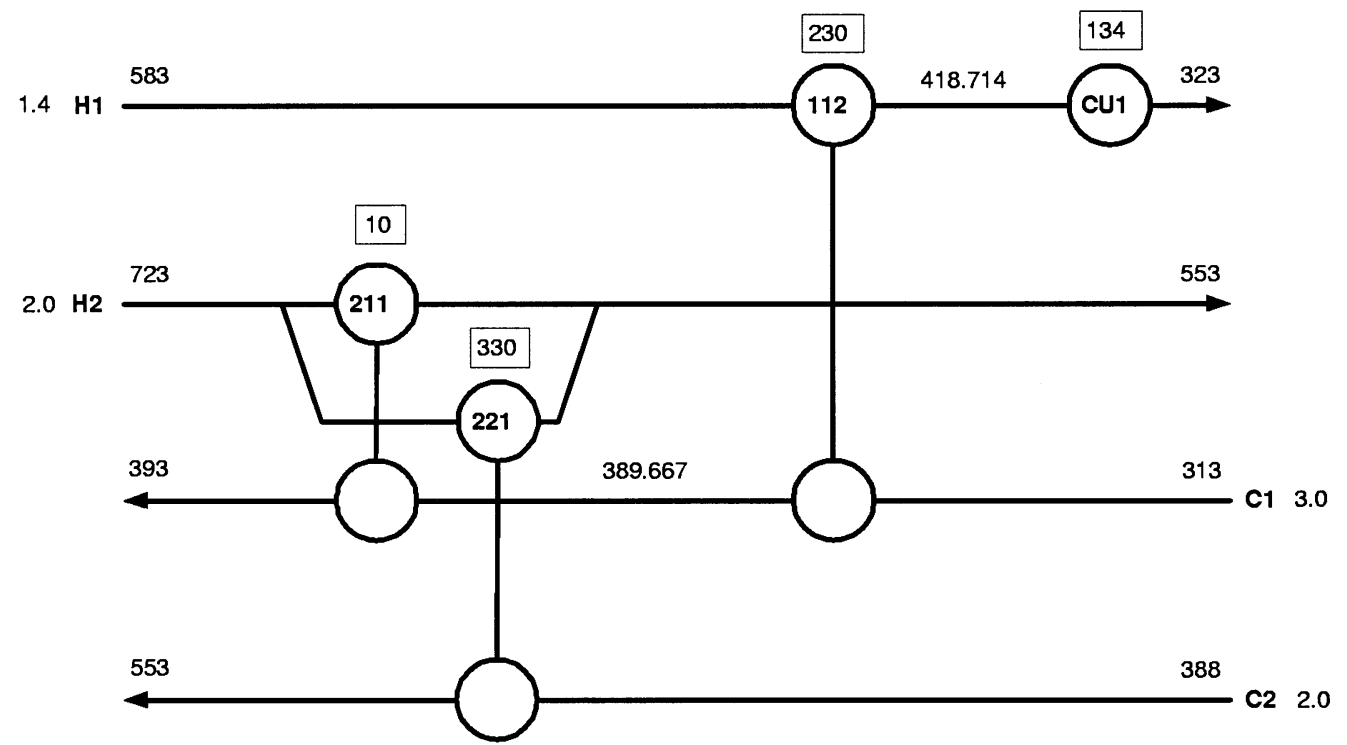

Figure 3. HEN structures for example 1 when considering the nominal conditions for synthesis. 


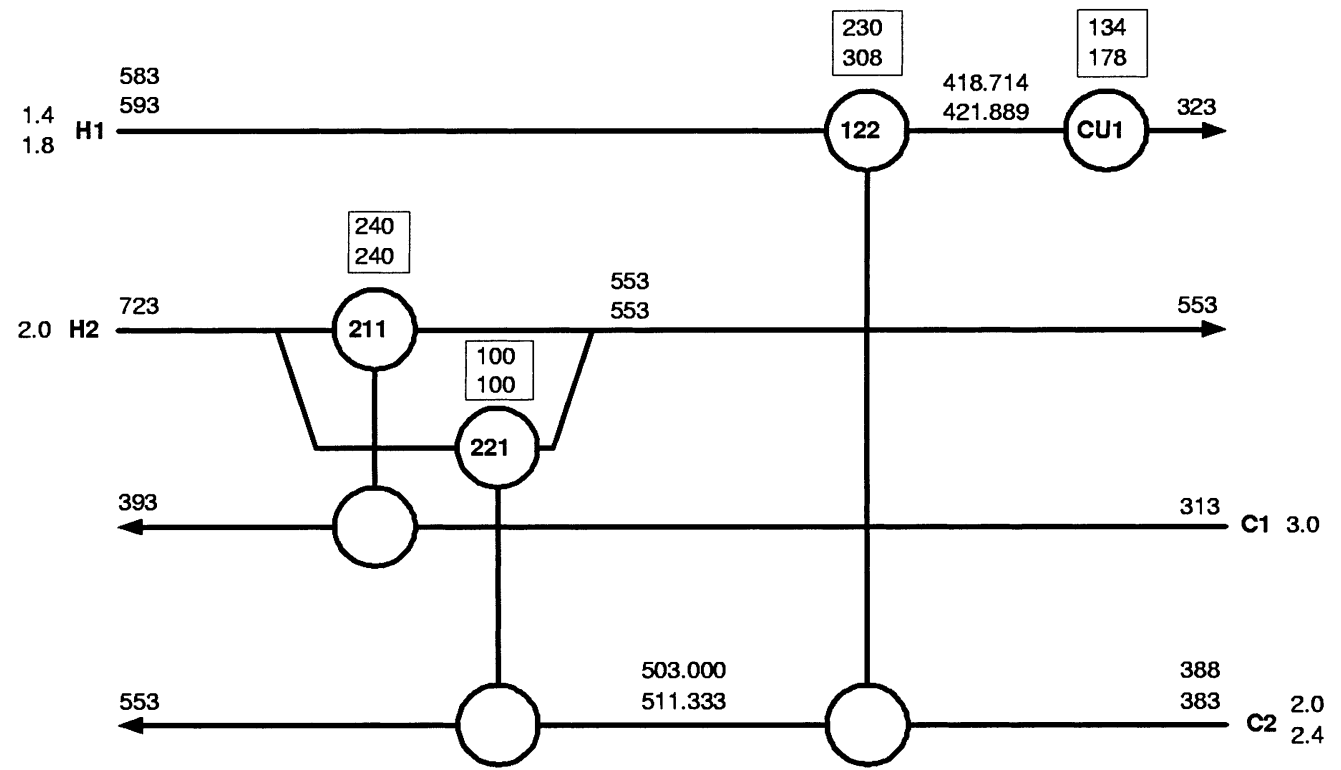

Figure 4. HEN structures for example 1 when considering the nominal conditions and period 1 for synthesis.

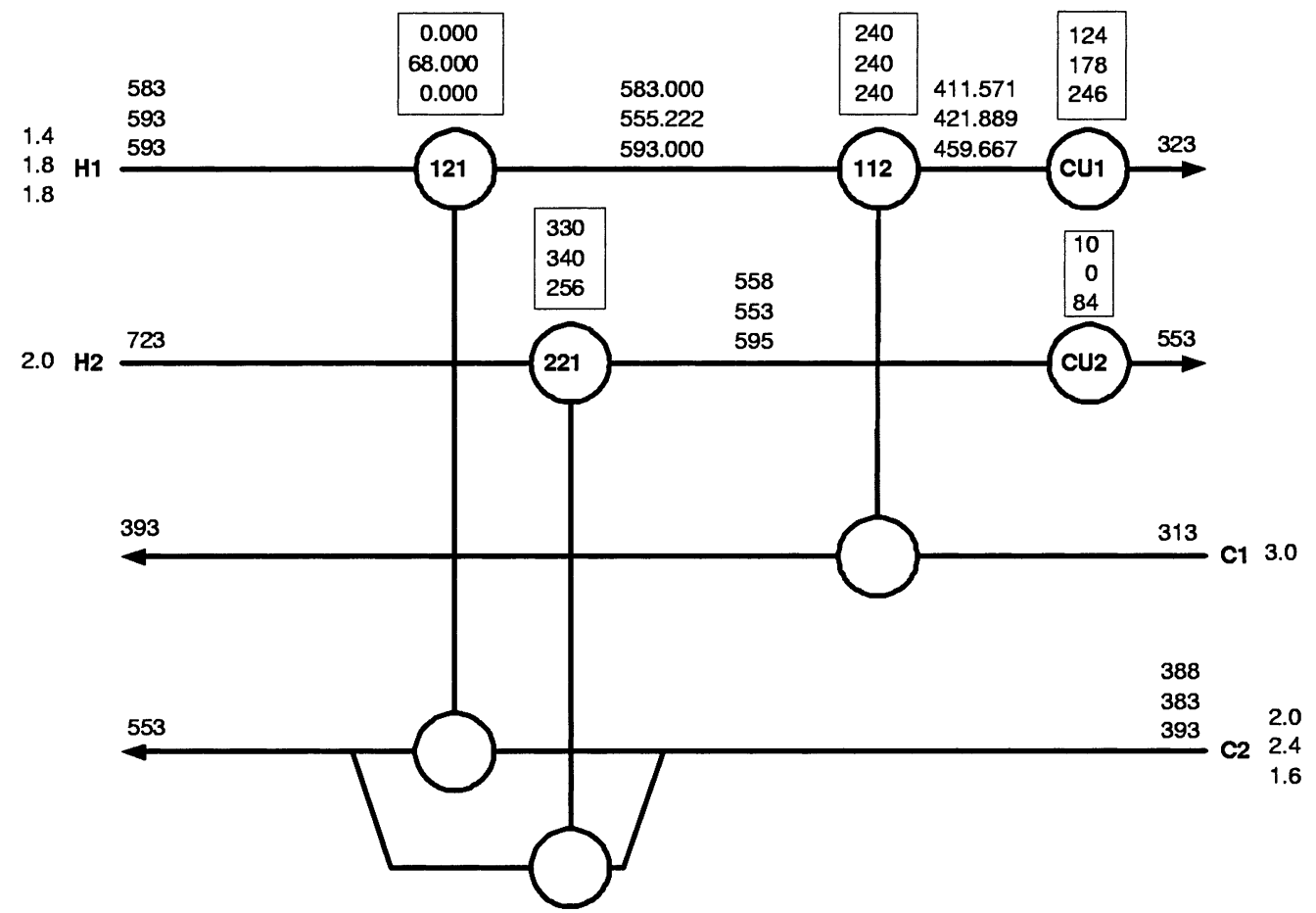

Figure 5. HEN structures for example 1 when considering the nominal conditions and periods 1 and 2 for synthesis.

periods 1 and 2 and the integer cuts for excluding the networks obtained from iterations 1 and 2, a new configuration is generated as shown in Figure 5 . It features a TAC of $\$ 37,274 \$ / y e a r$ and the set of selected units $\mathrm{SN}^{3}=\left\{\mathrm{z}_{112}^{3}, \mathrm{z}_{121}^{3}, \mathrm{z}_{221}^{3}, \mathrm{zcu}_{1}^{3}, \mathrm{zcu}_{2}^{3}\right\}$ with $\mathrm{n}_{\mathrm{SN}}^{3}=5$. Note that one additional cooler is joined because of the inclusion of maximizing the cooling load. To test for the feasibility of operation of this network, we found that there are seven equations and eight unknowns in constraint eqs 6 and 7; accordingly, one variable, say, $\mathrm{qCu}_{2}$, is selected as the control variable. A flexibility index value of $\mathscr{F}=0.6358$ is found by solving the nonlinear programming problem, eq 11, for each possible active set of constraints. Seeing that the network configuration is still less than feasible, in preparation for the next iteration, a new parameter point with the maximum heating load (i.e., $\mathrm{F}_{\mathrm{H} 1}^{\mathrm{L}}, \mathrm{F}_{\mathrm{C} 2}^{\mathrm{U}}, \mathrm{T}_{\mathrm{H} 1}^{\mathrm{L}}, \mathrm{T}_{\mathrm{C}_{2}}^{\mathrm{L}}$ ) is added, and the integer cuts are implemented to exclude networks 1-3 from consideration. The fourth iteration is then performed.

4. Iteration 4. Taking the nominal operating conditions and periods $1-3$ into consideration simultaneously and including the three integer cuts for excluding networks $1-3$ in solving eqs $2-4$ leads to the network shown in Figure 6. The TAC is $\$ 41,876 \$ / y e a r$, and $\mathrm{SN}^{4}$ $=\left\{\mathrm{z}_{112}^{4}, \mathrm{z}_{121}^{4}, \mathrm{z}_{221}^{4}, \mathrm{zCu}_{1}^{4}, \mathrm{zCu}_{2}^{4}, \mathrm{zhu}_{1}^{4}\right\}$ with $\mathrm{n}_{\mathrm{SN}}^{4}=6$. Notably, one heater is added because of the additional consideration of maximizing the heating load. This time, there are eight equations and 10 unknowns in eqs 6 and 7 for flexibility test; thus, two control variables are selected, say, $\mathrm{qCu}_{1}$ and $\mathrm{qcu}_{2}$. Then, solving the nonlinear 


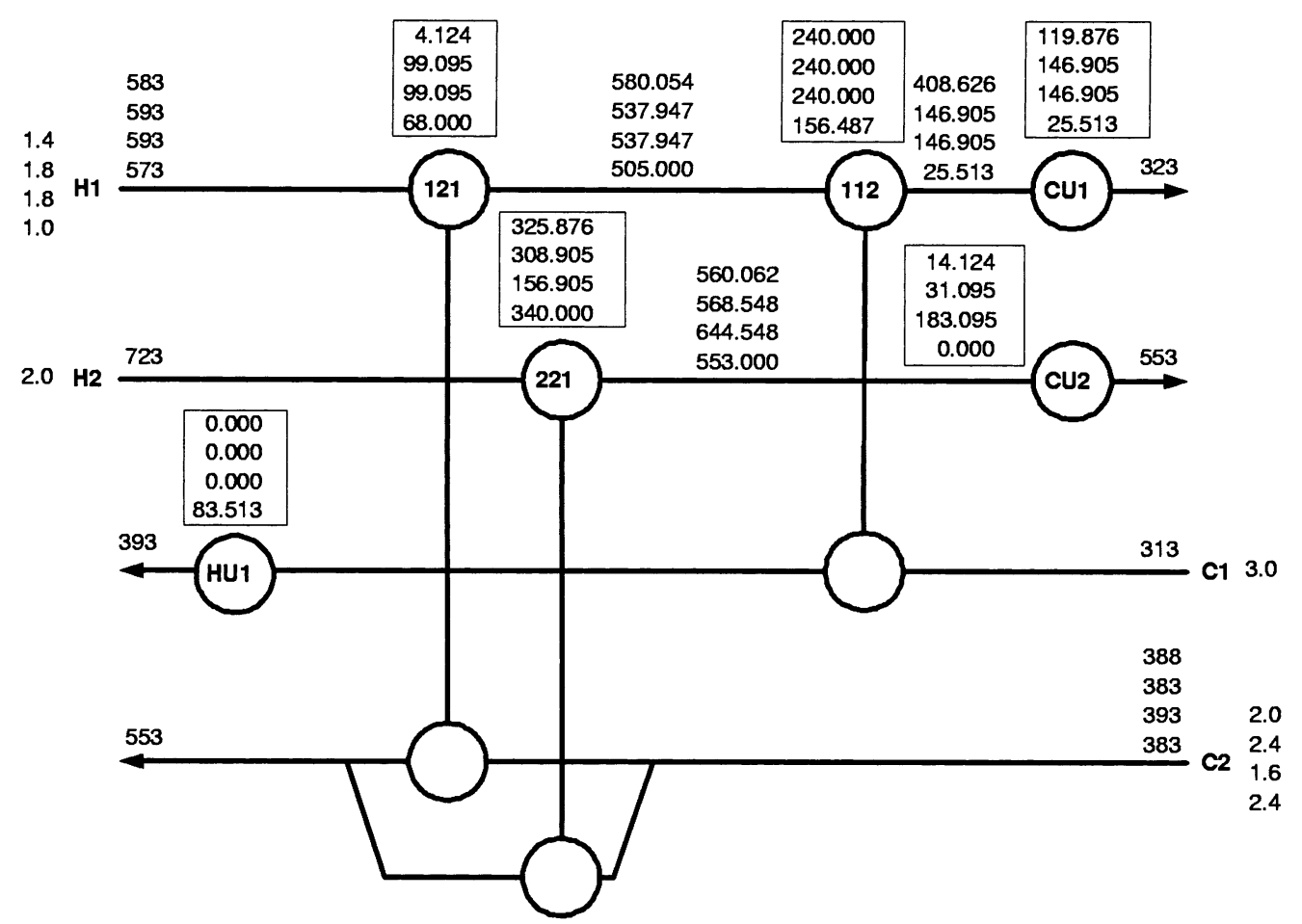

Figure 6. HEN structures for example 1 when considering the nominal conditions and periods $1-3$ for synthesis.

Table 3. Comparison of the Annual Capital Costs, Operating Costs, Total Annual Costs, and Flexibilities of the Resulting Networks for Example 1

\begin{tabular}{lcrrr}
\hline & $\begin{array}{c}\text { annual } \\
\text { capital } \\
\text { cost }\end{array}$ & $\begin{array}{c}\text { operating } \\
\text { cost }\end{array}$ & $\begin{array}{c}\text { total } \\
\text { annual } \\
\text { cost }\end{array}$ & flexibility \\
\hline nominal & 19,019 & 6,981 & 26,000 & 0.1311 \\
nominal + period 1 & 27,092 & 8,127 & 35,219 & 0.1847 \\
nominal + periods 1 and 2 & 26,125 & 11,149 & 37,274 & 0.6358 \\
nominal + periods 1-3 & 30,104 & 11,772 & 41,876 & 1.7134 \\
sequential & 39,380 & 10,499 & 49,879 & 1.0
\end{tabular}

Table 4. Cost Data for Example 2

\begin{tabular}{ll}
\hline \multicolumn{1}{c}{ cost parameter } & \multicolumn{1}{c}{ value } \\
\hline fuel cost & $204.732 \times 10^{-4} \$ / \mathrm{kWh}$ \\
cooling water cost & $60.576 \times 10^{-4} \$ / \mathrm{kWh}$ \\
operating time & $8,600 \mathrm{~h} / \mathrm{year}$ \\
exchanger capital costa & $4,333 \mathrm{~A}^{0.6}$ \\
furnace cost & $191.94(\mathrm{qhu})^{0.7}$ \\
capital annual factor & 0.2 \\
a A = exchanger area $\left(\mathrm{m}^{2}\right)$. &
\end{tabular}

programming problem, eq 11 , for each active set of constraints results in $\mathscr{F}=1.7134$. This value indicates that the network structure derived from the fourth synthesis step is not only economical, but also feasible for the overall operating space, which terminates the whole search process. The annual capital cost, the operating cost, the total annual cost, and the flexibility of resulting networks for example 1 are reported in Table 3 for comparison.

Example 2. A Six-Hot/One-Cold Streams ProbIem. This problem consists of six hot streams and one cold stream $\left(\mathrm{N}_{\mathrm{H}}=6, \mathrm{~N}_{\mathrm{C}}=1\right)$, al ong with fuel and cooling water as utilities. The problem data are listed in Tables 4 and 5 . Overall heat-transfer coefficients for process matches, $\mathrm{U}_{\mathrm{ij}}\left[\mathrm{kW} /\left(\mathrm{m}^{2} \mathrm{~K}\right)\right]$, are $\mathrm{U}_{11}=0.6, \mathrm{U}_{21}=0.4, \mathrm{U}_{31}$ $=0.3, U_{41}=0.4$, and $U_{61}=0.3$, and those for cold utility matches, $\mathrm{UCu}_{\mathrm{i}}$, are $\mathrm{U} \mathrm{Cu}_{1}=0.1, \mathrm{Ucu}_{5}=0.3$, and $\mathrm{UCu}_{6}=$ 0.4 . The minimum number of superstructure stages is $\mathrm{N}_{\mathrm{T}}=6$, as suggested. ${ }^{3}$ The desired range for uncertain
Table 5. Nominal Conditions for Example $2^{a}$

\begin{tabular}{cccc}
\hline & $\begin{array}{c}\text { heat-capacity } \\
\text { flow rate FCp } \\
\text { process streams }\end{array}$ & $\begin{array}{c}\text { input } \\
\text { temperature } \\
\mathrm{T} \text { in }(\mathrm{K})\end{array}$ & $\begin{array}{c}\text { output } \\
\text { temperature } \\
\mathrm{T} \text { out }(\mathrm{K})\end{array}$ \\
\hline hot stream 1 (H 1) & 9 & 630 & 460 \\
hot stream 2 (H2) & 6.5 & 550 & 480 \\
hot stream 3 (H3) & 3 & 530 & 480 \\
hot stream 4 (H4) & 36 & 470 & 400 \\
hot stream 5 (H5) & 7 & 450 & 310 \\
hot stream 6 (H6) & 72 & 410 & 350 \\
cold stream 1 (C1) & 27 & 310 & 650 \\
a $\Delta \mathrm{T}_{\text {min }}=10 \mathrm{~K}$ & & &
\end{tabular}

$$
\text { a } \Delta \mathrm{T}_{\min }=10 \mathrm{~K} \text {. }
$$

Table 6. Comparison of the Capital Costs, Operating Costs, Total Annual Costs, and the Flexibilities of the Resulting Networks for Example 2

\begin{tabular}{lcccc}
\hline & $\begin{array}{c}\text { annual } \\
\text { capital } \\
\text { cost }\end{array}$ & $\begin{array}{c}\text { operating } \\
\text { cost }\end{array}$ & $\begin{array}{c}\text { total } \\
\text { annual } \\
\text { cost }\end{array}$ & flexibility \\
\hline simultaneous & 107,991 & 755,080 & 863,071 & 1.2014 \\
sequential & 126,566 & 744,244 & 870,810 & 1.0
\end{tabular}

disturbances are assigned to be $\mathrm{FCp}=\mathrm{FCp}^{(0)} \pm 10 \%$ and $\mathrm{T}$ in $=\mathrm{T}$ in $(0) \pm 10 \mathrm{~K}$ for all hot/cold streams. Solving eqs 2-4 for the base case gives a network with a TAC of $\$ 863,071 \$ /$ year and selected units of $\mathrm{SN}^{1}=\left\{\mathrm{z}_{111}^{1}\right.$, $\left.z_{211}^{1}, z_{312}^{1}, z_{413}^{1}, z_{614}^{1}, z_{1}^{1}, z_{1}^{1}, z c u_{6}^{1}, z h u_{1}^{1}\right\}$, as shown in Figure 7. Constraint eqs 6 and 7 are then used to scrutinize the flexibility of this network. Given that there are 13 equations and 15 unknowns, two control variables $\left(\mathrm{n}_{\mathrm{u}}=2\right)$ can be selected, say, $\mathrm{qcu}_{1}$ and $\mathrm{qcu}_{6}$. $\mathrm{A}$ satisfactory value of $\mathscr{F}=1.2014$ is obtained from sol ving the nonlinear programming problem, eq 11, for each active set of constraints, so this network structure derived from the synthesis step is both economical and feasible for the full disturbance range. The costs and the flexibility of the network obtained via simultaneous design are reported in Table 6 for comparison with the result of sequential design. ${ }^{11}$ 


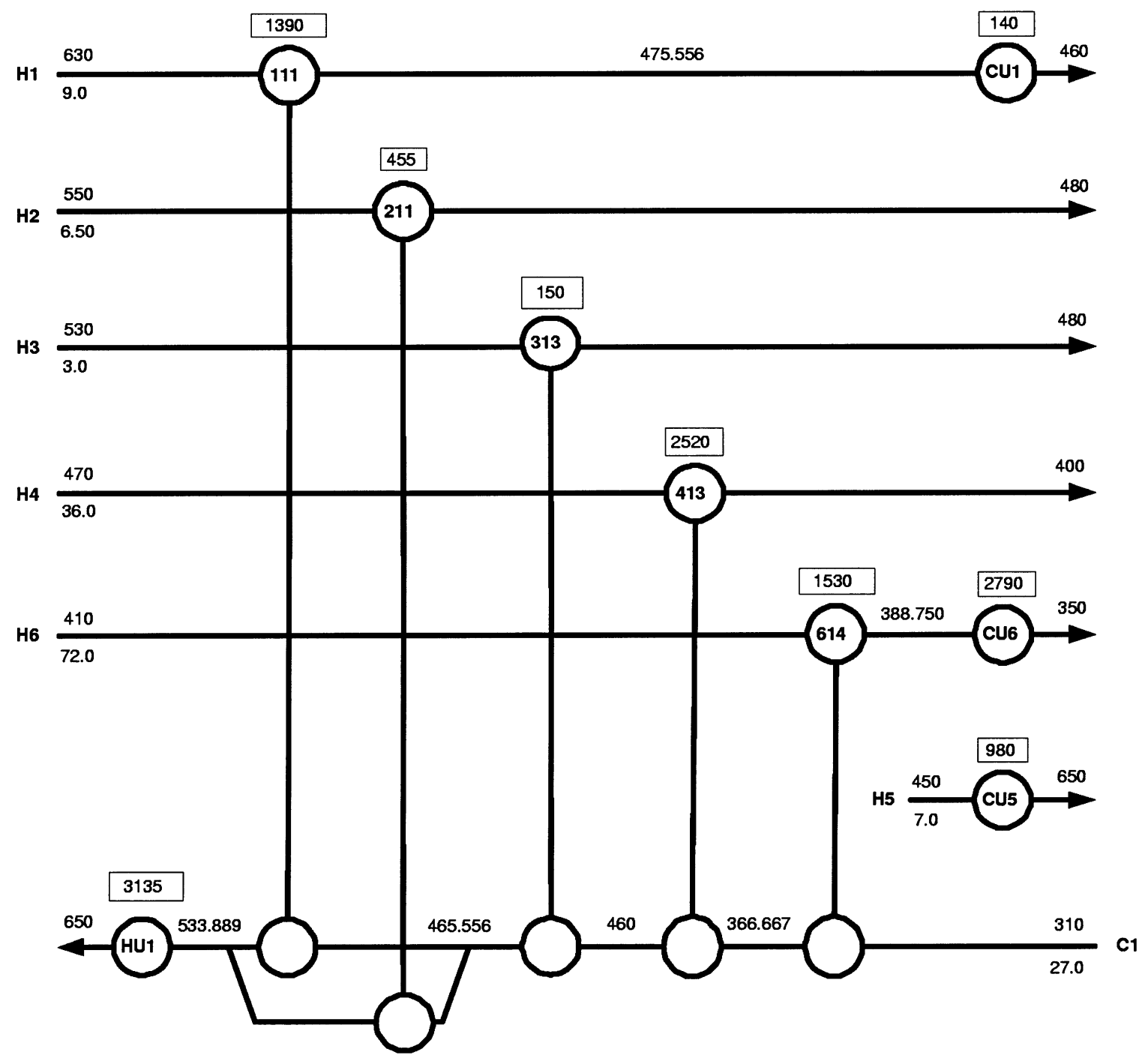

Figure 7. HEN structures for example 2 when considering the nominal conditions for synthesis.

\section{Conclusion}

In this paper, a new strategy has been proposed to synthesize flexible heat-exchange networks that involves uncertain source-stream temperatures and flow rates. The design problem is decomposed into iterative steps: First, the MINLP formulation is applied for the synthesis of a network configuration that bears the minimum total annual cost, with consideration of a finite number of extreme operating points that tend to maximize the need for heat exchangers, coolers, and heaters. Second, the active set strategy is employed for the flexibility analysis to test the operational feasibility of the resulting network over the full range of expected variations of the source-stream temperatures and flow rates. If the network structure does not meet the assigned flexibility target, then the current network is excluded by appending some integer cuts to the feasi ble network search space, and then the search process reverts to the synthesis step to find a new candidate network. Sometimes, several iterations are required to determine the final qualified network. By means of the two aforementioned numerical examples, we demonstrate that the proposed new strategy can generate a feasible network for uncertain supply temperatures and flow rates in a relatively more efficient way.

\section{Acknowledgment}

This work is supported by the National Science Council (ROC) under Contract NSC91-ET-7-002-004ET. Partial financial support of the Ministry of Economic Affairs under Grant 92-E C-17-A-09-S1-019 is also acknowl edged.

\section{Nomenclature}

Indices

$\mathrm{i}=$ hot process stream

$\mathrm{j}=$ cold process stream

$\mathrm{k}=$ superstructure stage

$\mathrm{n}=$ multiperiod limiting operating conditions

Sets

$\mathrm{AS}(\mathrm{k})=\mathrm{kth}$ index set of active constraints

$\mathrm{Cl}=$ index set of condensed inequalities

$\mathrm{CP}=$ set of cold process stream

$\mathrm{HP}=$ set of hot process streams

$\mathrm{N}_{\mathrm{AS}}=$ set of all possible combinations of active constraints

$\mathrm{SN}=$ set of selected units

ST $=$ set of superstructure stages

VT $=$ set of multiperiod operating conditions (base case included)

Parameters

$\mathrm{T}$ in $=$ inlet temperature of stream

$\mathrm{T}^{\text {out }}=$ outlet temperature of stream 
$\mathrm{FCp}=$ heat capacity flow rate

$\mathrm{N}_{\mathrm{C}}=$ number of cold streams

$\mathrm{N}_{\mathrm{H}}=$ number of hot streams

$\mathrm{N}_{\mathrm{T}}=$ number of superstructure stages

$\mathrm{N}_{\mathrm{V}}=$ number of operating conditions considered for mul-

tiperiod-based design

$\mathrm{U}=$ overall heat-transfer coefficient

$\Delta \mathrm{T}_{\min }=$ minimum approach temperature

$\Gamma=$ upper bound on the temperature difference

$\Lambda=$ upper bound on heat exchange

$\mathrm{V}=$ upper bound on slack variables

$\Delta \theta^{-}, \Delta \theta^{+}$scaled deviations from $\theta^{\mathbf{0}}$

Variables

$\mathscr{F}=$ flexibility index (a scalar)

$\mathrm{dt}_{\mathrm{ijk}}=$ temperature approach for match $\mathrm{i}$ and $\mathrm{j}$ in stage $\mathrm{k}$ at vertex $n$

$\mathrm{dtcu}_{\mathrm{i}}=$ temperature approach for match $\mathrm{i}$ and cold utility at vertex $n$

$\mathrm{dthu}_{\mathrm{j}}=$ temperature approach for match $\mathrm{j}$ and hot utility at vertex $n$

$\mathrm{q}_{\mathrm{ijk}}=$ heat exchanged between streams $\mathrm{i}$ and $\mathrm{j}$ in stage $\mathrm{k}$ at vertex $n$

$\mathrm{qcu}_{\mathrm{i}}=$ heat exchanged between stream $\mathrm{i}$ and cold utility at vertex $n$

$\mathrm{qhu}_{\mathrm{j}}=$ heat exchanged between stream $\mathrm{i}$ and hot utility at vertex $n$

$t_{i k}=$ temperature of stream $i$ at the hot end of stage $k$ at vertex $n$

$t_{j k}=$ temperature of stream $\mathrm{j}$ at the hot end of stage $\mathrm{k}$ at vertex $n$

$z_{i j k}=$ binary variable for the existence of a unit for matching streams $\mathrm{i}$ and $\mathrm{j}$ in stage $\mathrm{k}$

$\mathrm{zCu}_{\mathrm{i}}=$ binary variable for the existence of a unit for matching stream $\mathrm{i}$ and cold utility in stage $\mathrm{k}$

$z_{\text {hu }} \mathrm{i}_{\mathrm{i}}=$ binary variable for the existence of a unit for matching stream $\mathrm{j}$ and hot utility in stage $\mathrm{k}$

$\mathrm{n}_{\mathrm{AS}}=$ number of possible combinations of active sets

$\mathrm{n}_{\mathrm{SN}}=$ number of selected units

$\mathrm{n}_{\mathrm{R}}=$ number of rejected (disqualified) networks

$\delta=$ flexibility (scalar)

$\Omega=$ feasible region

Vectors

$\mathbf{d}=$ design variables

$\mathbf{h}=$ equality constraints

$\mathbf{g}=$ inequality constraints

$\mathbf{u}=$ control variables

$\mathbf{w}=$ state variables

$\mathbf{x}=$ variables

$\mathbf{z}=$ binary variables

$\theta=$ uncertain parameters

\section{Appendix A. Flexibility Analysis for Example 1}

1. Iteration 1. The equalities/inequalities, state variables, and reduced inequalities for the network of example 1 when considering the nominal conditions for synthesis are as follows

$\mathbf{h}^{(1)}(\mathbf{d}, \mathbf{u}, \mathbf{w}, \theta)=$

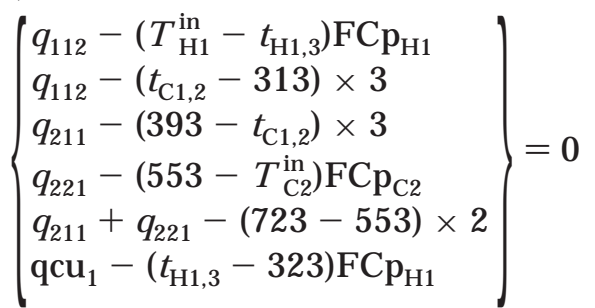

$$
\begin{aligned}
& \mathbf{g}^{(1)}(\mathbf{d}, \mathbf{u}, \mathbf{w}, \theta)=\left(\begin{array}{l}
\mathrm{t}_{\mathrm{H} 1,3}-\mathrm{T}_{\mathrm{H} 1}^{\text {in }} \\
323-\mathrm{t}_{\mathrm{H} 1,3} \\
\mathrm{t}_{\mathrm{C} 1,2}-393 \\
313-\mathrm{t}_{\mathrm{C} 1,2} \\
\mathrm{~T}_{\mathrm{C} 2}^{\text {in }}-553 \\
\Delta \mathrm{T}_{\min }+\mathrm{t}_{\mathrm{C} 1,2}-\mathrm{T}_{\mathrm{H} 1}^{\text {in }} \\
\Delta \mathrm{T}_{\text {min }}+313-\mathrm{t}_{\mathrm{H} 1,3} \\
\Delta \mathrm{T}_{\text {min }}+323-\mathrm{t}_{\mathrm{H}, 3} \\
\Delta \mathrm{T}_{\text {min }}+\mathrm{t}_{\mathrm{C} 1,2}-723 \\
\Delta \mathrm{T}_{\text {min }}+\mathrm{T}_{\mathrm{C} 2}-553
\end{array}\right) \leq 0 \\
& \mathbf{w}^{(1)}=\left\{\begin{array}{l}
w_{1} \\
w_{2} \\
w_{3} \\
w_{4} \\
w_{5} \\
w_{6}
\end{array}\right\}=\left\{\begin{array}{l}
q_{221} \\
q_{211} \\
t_{C 1,3} \\
q_{112} \\
t_{H 1,3} \\
q{ }_{1} u_{1}
\end{array}\right\}=\left\{\begin{array}{l}
\left(553-T_{C 2}^{\text {in }}\right) F C p_{C 2} \\
(723-553) \times 2-w_{1} \\
393-\frac{w_{2}}{3} \\
\left(w_{3}-313\right) \times 3 \\
T_{H 1}^{i n}-\frac{w_{4}}{F C p_{H 1}} \\
\left(w_{5}-323\right) F C p_{H 1}
\end{array}\right\} \\
& \mathbf{f}^{(1)}(\mathbf{d}, \mathbf{u}, \theta)=\left(\begin{array}{l}
\mathrm{W}_{5}-\mathrm{T}_{\mathrm{H} 1}^{\text {in }} \\
323-\mathrm{w}_{5} \\
\mathrm{~W}_{3}-393 \\
313-\mathrm{w}_{3} \\
\mathrm{~T}_{\mathrm{in}}-553 \\
\Delta \mathrm{T}_{\min }+\mathrm{w}_{3}-\mathrm{T}_{\mathrm{H} 1}^{\text {in }} \\
\Delta \mathrm{T}_{\min }+313-\mathrm{w}_{5} \\
\Delta \mathrm{T}_{\min }+323-\mathrm{w}_{5} \\
\Delta \mathrm{T}_{\min }+\mathrm{w}_{3}-723 \\
\Delta \mathrm{T}_{\min }+\mathrm{T}_{\mathrm{C} 2}^{\text {in }}-553
\end{array}\right) \leq 0
\end{aligned}
$$

There are 10 possible active sets in this case. The reduced inequalities and the associated flexibility index of each active set are listed in Table 7.

Table 7. Reduced Inequalities and the Associated Flexibility Index of Each Active Set for Example 1 When Considering the Nominal Data in Network Synthesis

\begin{tabular}{cccccc}
\hline$k$ & $A S(k)$ & $\delta^{k}$ & $k$ & $A S(k)$ & $\delta^{k}$ \\
\hline 1 & $f_{1}$ & 3.3156 & 6 & $f_{6}$ & 4.7610 \\
2 & $f_{2}$ & 0.6957 & 7 & $f_{7}$ & 0.6957 \\
3 & $f_{3}$ & 0.1311 & 8 & $f_{8}$ & 0.6358 \\
4 & $f_{4}$ & 3.3156 & 9 & $f_{9}$ & 5.3105 \\
5 & $f_{5}$ & 33.000 & 10 & $f_{10}$ & 33.000
\end{tabular}

2. Iteration 2. The equalities/inequalities, state variables, and reduced inequalities for the network of example 1 when considering the nominal conditions and period 1 for synthesis are as follows

$$
\mathbf{h}^{(2)}(\mathbf{d}, \mathbf{u}, \mathbf{w}, \theta)=\left\{\begin{array}{l}
\mathrm{q}_{122}-\left(\mathrm{T}_{\mathrm{H} 1}^{\mathrm{in}}-\mathrm{t}_{\mathrm{H} 1,3}\right) \mathrm{FCp}_{\mathrm{H} 1} \\
\mathrm{q}_{122}-\left(\mathrm{t}_{\mathrm{C} 2,2}-\mathrm{T}_{\mathrm{C} 2}\right) \mathrm{FCp}_{\mathrm{C} 2} \\
\mathrm{q}_{211}+\mathrm{q}_{221}-(723-553) \times 2 \\
\mathrm{q}_{211}-(393-313) \times 3 \\
\mathrm{q}_{221}-\left(553-\mathrm{t}_{\mathrm{C2}, 2}\right) \mathrm{FCp}_{\mathrm{C} 2} \\
\mathrm{qCu}_{1}-\left(\mathrm{t}_{\mathrm{H} 1,3}-323\right) \mathrm{FC} \mathrm{p}_{\mathrm{H} 1}
\end{array}\right\}=0
$$




$$
\begin{aligned}
& \mathbf{g}^{(2)}(\mathbf{d}, \mathbf{u}, \mathbf{w}, \theta)=\left(\begin{array}{l}
\mathrm{t}_{\mathrm{H} 1,3}-\mathrm{T}_{\mathrm{H} 1}^{\text {in }} \\
323-\mathrm{t}_{\mathrm{H} 1,3} \\
\mathrm{~T}_{\mathrm{C} 2}^{\text {in }}-\mathrm{t}_{\mathrm{C} 2,2} \\
\mathrm{t}_{\mathrm{C} 2,2}-553 \\
\Delta \mathrm{T}_{\min }+\mathrm{t}_{\mathrm{C} 2,2}-\mathrm{T}_{\mathrm{H} 1}^{\text {in }} \\
\Delta \mathrm{T}_{\min }+\mathrm{T}_{\mathrm{C} 2}-\mathrm{t}_{\mathrm{H} 1,3} \\
\Delta \mathrm{T}_{\min }+323-\mathrm{t}_{\mathrm{H} 1,3} \\
\Delta \mathrm{T}_{\min }+\mathrm{t}_{\mathrm{C} 2,2}-553
\end{array}\right) \leq 0 \\
& \mathbf{w}^{(2)}=\left\{\begin{array}{l}
w_{1} \\
w_{2} \\
w_{3} \\
w_{4} \\
w_{5} \\
w_{6}
\end{array}\right\}=\left\{\begin{array}{l}
q_{211} \\
q_{221} \\
t_{C 2,2} \\
q_{122} \\
t_{H 1,3} \\
q q_{1}
\end{array}\right\}=\left\{\begin{array}{l}
(393-313) \times 3 \\
(723-553) \times 2-w_{1} \\
553-\frac{w_{2}}{F C p_{C 2}} \\
\left(w_{3}-T_{\text {in }}\right) F C p_{C 2} \\
T_{H 1}^{\text {in }}-\frac{w_{4}}{F C p_{H 1}} \\
\left(w_{5}-323\right) F C p_{H 1}
\end{array}\right\} \\
& \mathbf{f}^{(2)}(\mathbf{d}, \mathbf{u}, \theta)=\left(\begin{array}{l}
\mathrm{W}_{5}-\mathrm{T}_{\mathrm{H} 1}^{\text {in }} \\
323-\mathrm{W}_{5} \\
\mathrm{~T}_{\mathrm{C}}^{\text {in }}-\mathrm{W}_{3} \\
\mathrm{~W}_{3}-553 \\
\Delta \mathrm{T}_{\text {min }}+\mathrm{W}_{3}-\mathrm{T}_{\mathrm{H} 1}^{\text {in }} \\
\Delta \mathrm{T}_{\text {min }}+\mathrm{T}_{\mathrm{C}}-\mathrm{W}_{5} \\
\Delta \mathrm{T}_{\text {min }}+323-\mathrm{w}_{5} \\
\Delta \mathrm{T}_{\text {min }}+\mathrm{w}_{3}-553
\end{array}\right) \leq 0
\end{aligned}
$$

The reduced inequalities and the associated flexibility index of each active set are reported in Table 8.

Table 8. Reduced Inequalities and the Associated Flexibility Index of Each Active Set for Example 1 When Considering the Nominal Data and Period 1 in Network Synthesis

\begin{tabular}{ccc}
\hline$k$ & $A S(k)$ & $\delta^{k}$ \\
\hline 1 & $f_{1}$ & 3.3156 \\
2 & $f_{2}$ & 0.6957 \\
3 & $f_{3}$ & 3.3156 \\
4 & $f_{4}$ & - \\
5 & $f_{5}$ & 4.6033 \\
6 & $f_{6}$ & 0.1847 \\
7 & $f_{7}$ & 0.6358 \\
8 & $f_{8}$ & 20.000
\end{tabular}

3. Iteration 3. The equalities/inequalities, state variables, and reduced inequalities for the network of example 1 when considering the nominal conditions and periods 1 and 2 for synthesis are as follows

$\mathbf{h}^{(3)}(\mathbf{d}, \mathbf{u}, \mathbf{w}, \theta)=$

$$
\left\{\begin{array}{l}
q_{121}-\left(T_{H 1}-t_{H 1,2}\right) F C p_{H 1} \\
q_{112}-\left(t_{H 1,2}-t_{H 1,3}\right) F C p_{H 1} \\
q_{112}-(393-313) F C p_{C 1} \\
q_{221}-\left(723-t_{H 2,2}\right) \times 2 \\
q_{121}+q_{221}-\left(553-T_{C 2}^{\text {in }}\right) F C p_{C 2} \\
q \mathrm{qu}_{1}-\left(t_{H 1,3}-323\right) F C p_{H 1} \\
q \mathrm{qu}_{2}-\left(t_{H 2,2}-553\right) F C p_{H 2}
\end{array}\right\}=0
$$

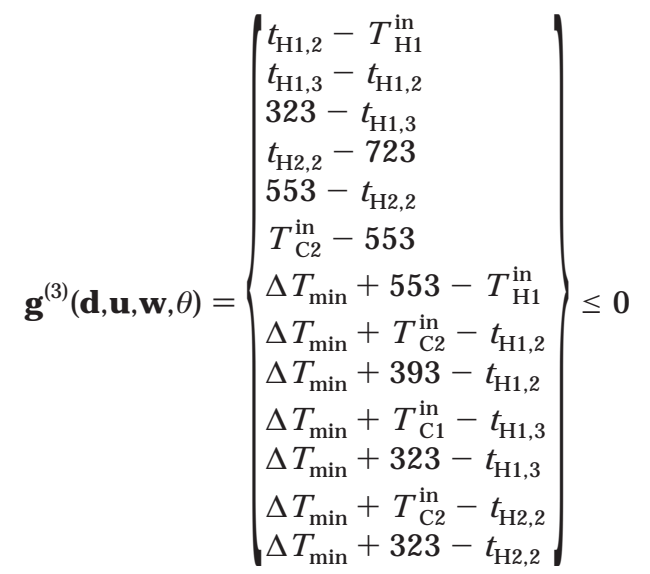

$$
\begin{aligned}
& \mathbf{w}^{(3)}=\left\{\begin{array}{l}
w_{1} \\
w_{2} \\
w_{3} \\
w_{4} \\
w_{5} \\
w_{6} \\
w_{7}
\end{array}\right\}=\left\{\begin{array}{l}
t_{H 2,2} \\
q_{221} \\
q_{121} \\
t_{H 1,2} \\
q_{112} \\
t_{H 1,3} \\
q C u_{1}
\end{array}\right\}=\left\{\begin{array}{l}
553+\frac{q^{2} u_{2}}{2} \\
\left(723-w_{1}\right) \times 2 \\
\left(553-T{ }_{C 2}\right) F C p_{C 2}-w_{2} \\
T \text { in }-\frac{w_{3}}{F C p_{H 1}} \\
(393-313) \times 3 \\
w_{4}-\frac{w_{5}}{F C p_{H 1}} \\
\left(w_{6}-323\right) F C p_{H 1}
\end{array}\right\}
\end{aligned}
$$

The signs of the sensitivities for these reduced inequalities to the control variable, the inequalities, and the associated flexibility index of each active set are re ported in Tables 9 and 10.

Table 9. Signs of $\partial \mathrm{f}_{\mathrm{m}} / \partial \mathrm{qcu}$ for Example 1 When Considering the Nominal Data and Periods 1 and 2 in Network Synthesis

\begin{tabular}{ccc}
\hline & $\partial \mathrm{f}_{\mathrm{m}} / \partial \mathrm{qcu} \mathrm{u}_{2}$ & \\
\cline { 2 - 3 }$>0$ & $<0$ & $=0$ \\
\hline $\mathrm{f}_{3}$ & $\mathrm{f}_{1}$ & $\mathrm{f}_{2}$ \\
$\mathrm{f}_{4}$ & $\mathrm{f}_{5}$ & $\mathrm{f}_{6}$ \\
$\mathrm{f}_{8}$ & $\mathrm{f}_{12}$ & $\mathrm{f}_{7}$ \\
$\mathrm{f}_{9}$ & $\mathrm{f}_{13}$ & \\
$\mathrm{f}_{10}$ & & \\
$\mathrm{f}_{11}$ & &
\end{tabular}

4. Iteration 4. The equalities/inequalities, state variables, and reduced inequalities for the network of example 1 when considering the nominal conditions and 
Table 10. Reduced Inequalities and Associated Flexibility Indexes of Each Active Set for Example 1 When Considering the Nominal Data and Periods 1 and 2 in Network Synthesis

\begin{tabular}{rlcclc}
\hline $\mathrm{k}$ & $\mathrm{AS}(\mathrm{k})$ & $\delta^{\mathrm{k}}$ & $\mathrm{k}$ & $\mathrm{AS}(\mathrm{k})$ & $\delta^{\mathrm{k}}$ \\
\hline 1 & $\mathrm{f}_{1}, \mathrm{f}_{3}$ & 1.0912 & 13 & $\mathrm{f}_{12}, \mathrm{f}_{3}$ & 31.0 \\
2 & $\mathrm{f}_{1}, \mathrm{f}_{4}$ & 33.000 & 14 & $\mathrm{f}_{12}, \mathrm{f}_{4}$ & 65.0 \\
3 & $\mathrm{f}_{1}, \mathrm{f}_{8}$ & 12.333 & 15 & $\mathrm{f}_{12}, \mathrm{f}_{8}$ & 31.0 \\
4 & $\mathrm{f}_{1}, \mathrm{f}_{9}$ & 18.000 & 16 & $\mathrm{f}_{12}, \mathrm{f}_{9}$ & 31.0 \\
5 & $\mathrm{f}_{1}, \mathrm{f}_{10}$ & 1.0912 & 17 & $\mathrm{f}_{12}, \mathrm{f}_{10}$ & 31.0 \\
6 & $\mathrm{f}_{1}, \mathrm{f}_{11}$ & 1.0000 & 18 & $\mathrm{f}_{12}, \mathrm{f}_{11}$ & 31.0 \\
7 & $\mathrm{f}_{5}, \mathrm{f}_{3}$ & 0.6957 & 19 & $\mathrm{f}_{13}, \mathrm{f}_{3}$ & - \\
8 & $\mathrm{f}_{5}, \mathrm{f}_{4}$ & - & 20 & $\mathrm{f}_{13}, \mathrm{f}_{4}$ & - \\
9 & $\mathrm{f}_{5}, \mathrm{f}_{8}$ & 1.7134 & 21 & $\mathrm{f}_{13}, \mathrm{f}_{8}$ & - \\
10 & $\mathrm{f}_{5}, \mathrm{f}_{9}$ & 1.6509 & 22 & $\mathrm{f}_{13}, \mathrm{f}_{9}$ & - \\
11 & $\mathrm{f}_{5}, \mathrm{f}_{10}$ & 0.6957 & 23 & $\mathrm{f}_{13}, \mathrm{f}_{10}$ & - \\
12 & $\mathrm{f}_{5}, \mathrm{f}_{11}$ & 0.6358 & 24 & $\mathrm{f}_{13}, \mathrm{f}_{11}$ & -
\end{tabular}

periods $1-3$ for synthesis are as follows

$$
\begin{aligned}
& \mathbf{h}^{(4)}(\mathbf{d}, \mathbf{u}, \mathbf{w}, \theta)=
\end{aligned}
$$

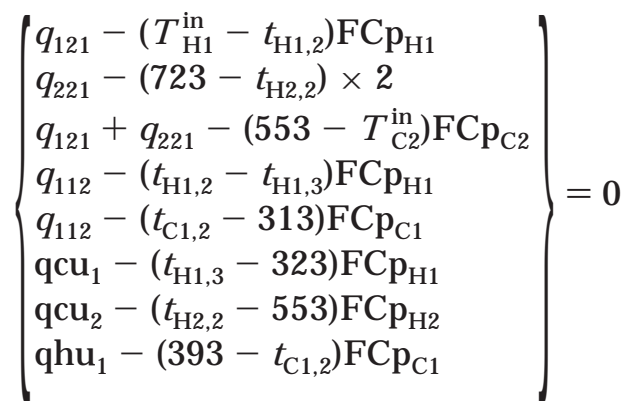

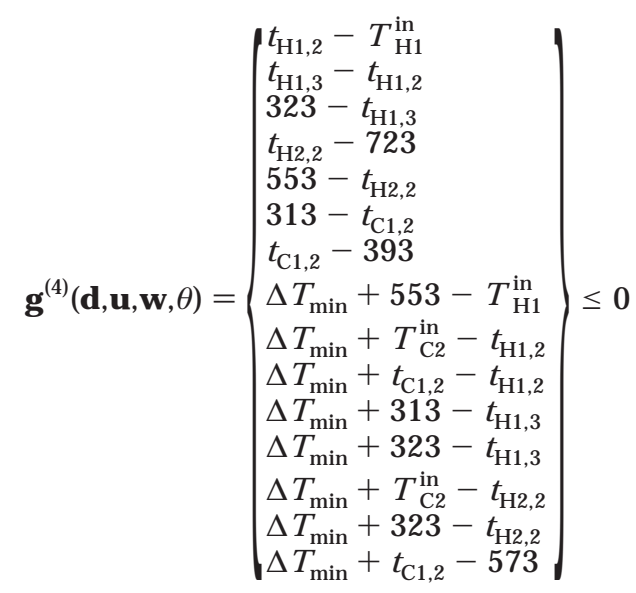

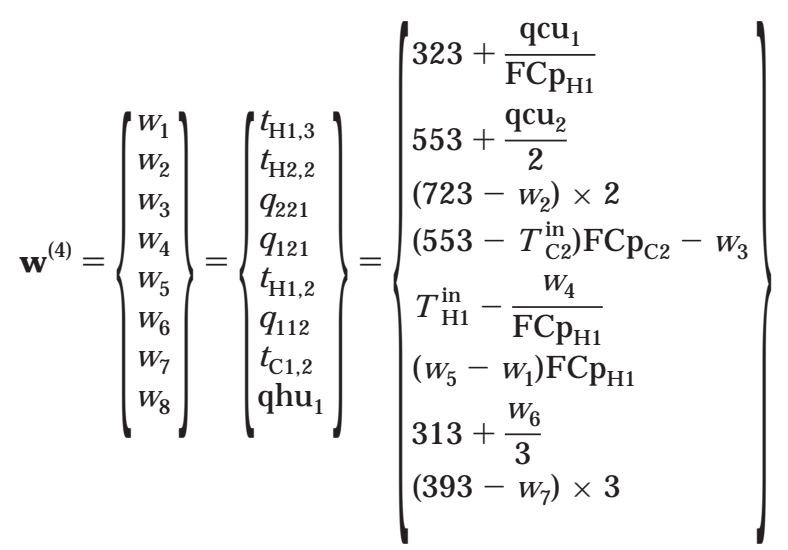

$$
\mathbf{f}^{(4)}(\mathbf{d}, \mathbf{u}, \theta)=\left|\begin{array}{l}
\mathrm{W}_{5}-\mathrm{T}_{\mathrm{H}} \\
\mathrm{W}_{1}-\mathrm{W}_{5} \\
323-\mathrm{w}_{1} \\
\mathrm{w}_{2}-723 \\
553-\mathrm{w}_{2} \\
313-\mathrm{w}_{7} \\
\mathrm{~W}_{7}-393 \\
\Delta \mathrm{T}_{\min }+553-\mathrm{T}_{\mathrm{H} 1}^{\text {in }} \\
\Delta \mathrm{T}_{\min }+\mathrm{T}_{\mathrm{C} 2}-\mathrm{w}_{5} \\
\Delta \mathrm{T}_{\min }+\mathrm{t}_{\mathrm{C} 1,2}-\mathrm{w}_{5} \\
\Delta \mathrm{T}_{\min }+313-\mathrm{w}_{1} \\
\Delta \mathrm{T}_{\min }+323-\mathrm{w}_{1} \\
\Delta \mathrm{T}_{\min }+\mathrm{T}_{\mathrm{C} 2}-\mathrm{w}_{2} \\
\Delta \mathrm{T}_{\min }+323-\mathrm{w}_{2} \\
\Delta \mathrm{T}_{\min }+\mathrm{W}_{7}-573
\end{array}\right| \leq 0
$$

The signs of the sensitivity function for these inequalities to the control variable are reported in Tables 9-12. With two control variables, there are more than 100 possible combinations of active sets. The inequalities and the associated flexibility indices of the active sets are listed in Table 12.

\begin{tabular}{|c|c|c|c|c|c|c|}
\hline \multicolumn{3}{|c|}{$\partial f_{m} / \partial q c u_{1}$} & \multirow{2}{*}{ - } & \multicolumn{3}{|c|}{$\partial f_{m} / \partial q c u_{2}$} \\
\hline$>0$ & $<0$ & $=0$ & & $>0$ & $<0$ & $=0$ \\
\hline $\begin{array}{l}f_{2} \\
f_{6}\end{array}$ & $\begin{array}{l}\mathrm{f}_{3} \\
\mathrm{f}_{7} \\
\mathrm{f}_{10} \\
\mathrm{f}_{11} \\
\mathrm{f}_{12} \\
\mathrm{f}_{15}\end{array}$ & $\begin{array}{l}f_{1} \\
f_{4} \\
f_{5} \\
f_{8} \\
f_{9} \\
f_{13} \\
f_{14}\end{array}$ & & $\begin{array}{l}\mathrm{f}_{2} \\
\mathrm{f}_{4} \\
\mathrm{f}_{6} \\
\mathrm{f}_{9} \\
\mathrm{f}_{10}\end{array}$ & $\begin{array}{l}\mathrm{f}_{1} \\
\mathrm{f}_{5} \\
\mathrm{f}_{7} \\
\mathrm{f}_{13} \\
\mathrm{f}_{14} \\
\mathrm{f}_{15}\end{array}$ & $\begin{array}{l}f_{3} \\
f_{8} \\
f_{11} \\
f_{12}\end{array}$ \\
\hline
\end{tabular}

Table 11. Signs of $\partial f_{m} / \partial q c u_{1}$ and $\partial f_{m} / \partial q c u_{2}$ for Example 1 When Considering the Nominal Data and Periods 1-3 in Network Synthesis

Table 12. Reduced Inequalities and Associated Flexibility Indexes for Some Active Sets for Example 1 When Considering the Nominal Data and Periods $1-3$ in Network Synthesis

\begin{tabular}{ccc}
\hline$k$ & $A S(k)$ & \multicolumn{1}{c}{$\delta^{k}$} \\
\hline 1 & $f_{1}, f_{5}, f_{9}$ & - \\
2 & $f_{2}, f_{5}, f_{9}$ & 1.7134 \\
3 & $f_{3}, f_{5}, f_{9}$ & 1.7134 \\
4 & $f_{4}, f_{5}, f_{9}$ & - \\
5 & $f_{5}, f_{6}, f_{9}$ & 1.7134 \\
6 & $f_{5}, f_{7}, f_{9}$ & 5.5310 \\
7 & $f_{5}, f_{9}, f_{10}$ & 5.5354 \\
8 & $f_{5}, f_{9}, f_{11}$ & 1.7134 \\
9 & $f_{5}, f_{9}, f_{13}$ & -
\end{tabular}

\section{Literature Cited}

(1) Linnhoff, B.; Hindmarsh, E. The pinch design method for heat exchanger networks. Chem. Eng. Sci. 1983, 38, 745.

(2) Floudas, C. A.; Ciric, A. R.; Grossmann, I. E. Automatic Synthesis of Optimum Heat Exchanger Network Configurations. AIChE J . 1986, 32, 276.

(3) Yee, T. F.; Grossmann, I. E.; Kravanja, Z. Simultaneous optimization models for heat integration-I. Area and energy targeting and modeling of multi-stream exchangers. Comput. Chem. Eng. 1990, 14, 1151.

(4) Yee, T. F.; Grossmann, I. E. Simultaneous optimization models for heat integration-II. Heat exchanger network synthesis. Comput. Chem. Eng. 1990, 14, 1165.

(5) Grossmann, I. E.; Caballero, J . A.; Yeomans, H. Mathematical programming approaches to the synthesis of chemical process systems. Korean J . Chem. Eng. 1999, 16 (4), 407.

(6) Furman, K. C.; Sahinidis, N. V. A critical review and annotated bibliography for heat exchanger network synthesis in the 20th century. Ind. Eng. Chem. Res. 2002, 41, 2335. 
(7) Marselle, D. F.; Morari, M.; Rudd, D. F. Design of resilient processing plants-II: Design and control of energy management systems. Chem. Eng. Sci. 1982, 37, 259.

(8) Grossmann, I. E.; Halemane, K. P.; Swaney, R. E., Optimization strategies for flexible chemical process. Comput. Chem. Eng. 1983, 439.

(9) Swaney, R. E.; Grossmann, I. E. An index for operational flexibility in chemical process design. Part I. Formulation and theory. AlChE J . 1985, 31, 621.

(10) Grossmann, I. E.; Floudas, C. A. Active constraint strategy for flexibility analysis in chemical processes. Comput. Chem. Eng. 1987, 11, 675.

(11) Floudas, C. A.; Grossmann, I. E. Synthesis of flexible heat exchanger networks with uncertain flowrates and temperatures. Comput. Chem. Eng. 1987, 11, 319.

(12) Aaltola, J. Simultaneous synthesis of flexible heat exchanger network. Appl. Therm. Eng. 2002, 22, 907.

(13) Halemane, K. P.; Grossmann, I. E. Optimal process design under uncertainty. AIChE J . 1983, 29, 425.

(14) Floudas, C. A. Nonlinear and Mixed-Integer Optimization: Fundamentals and Applications; Oxford University Press: New York, 1995.
(15) Biegler, L. T.; Grossmann, I. E.; Westerberg, A. W. Systematic Methods of Chemical Process Design; Prentice Hall: Upper Saddle River, NJ , 1997.

(16) Chen, J . J . J . Letter to the editor: Comments on improvement on a replacement for the logarithmic mean. Chem. Eng. Sci. 1987, 2488.

(17) Konukman, A. E. S.; Camurdan, M. C.; Akman, U. Simultaneous flexibility targeting and synthesis of minimumutility heat-exchanger networks with superstructure-based MILP formulation. Chem. Eng. Process. 2002, 41, 501.

(18) Brooke, A.; Kendrick. D.; Meeraus, A.; Raman, R.; Rosenthal, R. E. GAMS: A User's Guide; Scientific Press: Redwood City, CA, 1998.

Received for review September 2, 2003 Revised manuscript received May 28, 2004 Accepted J une 9, 2004

IE030701F 